\title{
INTERTEXTUALIDADE E POLIFONIA NO FILME FRANKENSTEIN: ENTRE ANJOS E DEMÔNIOS
}

\author{
Rangel Ramiro Ramos ${ }^{1}$ \\ Carolina Fernandes da Silva Mandaji ${ }^{2}$
}

\begin{abstract}
Resumo
O presente artigo se propõe a fazer uma análise discursiva da Teologia e dos elementos religiosos presentes no filme Frankenstein: Entre anjos e demônios. Para isso, serão utilizados dois conceitos da Análise do Discurso: a Intertextualidade e a Polifonia. O objetivo desta pesquisa é demonstrar o dialogismo e a heterogeneidade entre o discurso religioso e a produção cinematográfica.

Palavras-chave: Análise do discurso, heterogeneidade, religião, cinema, teologia.
\end{abstract}

\begin{abstract}
This article aims at analyzing the theological and religious elements in the movie "Frankenstein". In order to do that, we used as a theoretical reference the concepts of intertextuality and polyphony, from discourse analysis. The objective of this analysis é to demonstrate dialogism and heterogeneity between religious discourse and cinematographic production.

Keywords: Discourse analysis, heterogeneity, religion, cinema, theology.
\end{abstract}

\section{Introdução}

Para Bakhtin (2011), o falante não é um Adão mítico, que aborda com sua primeira fala objetos virgens de um mundo ainda não posto em questão, aos quais dá nome pela primeira vez. Somente este Adão mítico estaria em condição de ser ele próprio produtor de um discurso isento do "já dito" na fala do outro. Tal definição proposta por Bakhtin nos permite refletir sobre o dialogismo e os discursos, presentes nos diferentes textos por meio da heterogeneidade e da polifonia, e demonstrado na intertextualidade dos textos a serem analisados neste trabalho.

Para isso, o objeto analisado é o filme do diretor Stuart Beattie, a releitura mais recente da história épica de Frankenstein, de 1818, da escritora londrina Mary Shelley. O longa-metragem estreou em janeiro de 2014, e foi intitulado: Frankenstein: entre anjos e demônios. O que se propõe, através da análise discursiva, é apresentar o filme como heterogêneo, identificando para isso elementos de recontextualização e reapresentação do romance de Mary Shelley, trazendo em sua proposta o “já dito" das

\footnotetext{
${ }^{1}$ Bacharel em Teologia pela Faculdade Batista do Paraná e Graduando em Comunicação Institucional pela Universidade Tecnológica Federal do Paraná.

${ }^{2}$ Doutora em Semiótica e Comunicação (PUC-SP), professora do Departamento de Comunicação e Linguagem da UTFPR-Curitiba.
} 
discussões rudimentares da teologia cristã, como: a vida, a morte, o criacionismo, a rebeldia humana e o dualismo entre o bem e o mau.

Na sua composição no século XIX, a história de Frankenstein já versava sobre conceitos teológicos, como: a criação do ser humano, a rebeldia do homem contra o seu criador e a maldade intrínseca na natureza humana. Entretanto, na releitura de 2014, além das abordagens tradicionais, o enredo da história apresenta também as suposições religiosas da guerra invisível entre as criaturas divinas e as criaturas diabólicas, assim como a hipótese de uma iminente batalha final entre o bem e o mal, latente no discurso cristão e elaborada a partir das ideias maniqueístas.

A teologia é tão presente no filme que quando questionado sobre em que estaria baseado o filme de 2014, o roteirista Kevin Grevioux afirmou que a história do filme estaria embasada na Bíblia ${ }^{3}$. Portanto, para tornar explícitos os pressupostos teológicos apresentados pelo filme serão utilizados dois conceitos da Análise do Discurso (AD) como ferramenta de pesquisa: a intertextualidade e a polifonia, conceituadas a partir de Mikhail Bakhtin e desenvolvidas por Jacqueline Authier-Revuz.

Para uma construção efetiva de pensamento científico, esta pesquisa se limita a trabalhar os conceitos da $\mathrm{AD}$, citados acima, em apenas dois recortes do filme. Como ferramenta analítica, propõem-se dois questionamentos: 1) se a escolha do nome Adam para o monstro de Frankenstein teria relação ou não com o nome dado ao primeiro homem da Bíblia, 2) se há ou não relação da gárgula com seres míticos e transcendentes.

Primeiramente, nos apontamentos teológicos de criação da humanidade e a relação do homem com seu criador que estão presentes no nome do personagem principal do filme, Adam. O segundo recorte trabalhará com os elementos semióticos e discursivos da gárgula, que é retratado como anjo, apoiando-se na construção de sentido a partir da arquitetura gótica. A pesquisa tem por objetivo analisar, ainda, as construções de significado a partir das concepções teológicas clássicas que surgem dentro do enunciado produzido pelo filme. A proposta é utilizar a Análise do Discurso para fundamentar a relação entre teologia e o filme analisado.

\section{Sobre a história}

Na releitura de Stuart Beattie, a criatura de Victor Frankenstein, depois da morte do seu criador, se vê como em dois universos paralelos, a realidade e a metafísica. Os

\footnotetext{
${ }^{3}$ Disponível em: http://www.youtube.com/watch?v=KGfVci79j2c, acessado em 20 de março de 2014.
} 
anjos e demônios indicados no título do filme são seres que transitam nesses dois universos, mas não são percebidos pelos humanos como seres metafísicos.

Por não ter sido criado por Deus, mas pelo homem, Adam (o monstro de Frankenstein) vive, mas sem "alma". Por isso, transita no espaço existente em meio à guerra travada pelos anjos e demônios. O fato de ser desprovido de alma dá a Adam a possibilidade de fazer "ascender" o anjo ou "descender" os demônios, pois por não serem vivos como humanos, logo não poderiam ser mortos. Adam não é humano, mas também não é metafísico, porém consegue interagir paradoxalmente nos dois contextos.

Naberius, o demônio superior, se prepara para a batalha final, calcado na possibilidade de um ser sem alma ganhar vida, tentativa que foi erigida por Victor Frankenstein e consumada no momento em que Adam deu o primeiro suspiro. Naberius cria um exército de criaturas sem alma, desejando que tais criaturas sirvam como hospedeiras de demônios reerguidos das trevas, porém esbarra nas tentativas de fazer viver tais criaturas. O monstro de Frankenstein pode ser a peça que falta para Naberius atingir seu objetivo. Já os anjos liderados por Leonore lutam para preservar a autonomia criadora de Deus e as leis celestiais preestabelecidas em relação à humanidade.

A maior parte do filme se passa em Paris, tendo a catedral de Notre Dame como quartel-general da ordem gárgula, os anjos. O filme começa localizado temporalmente no que parece ser o século XIX, e depois de ter seu primeiro contato com as criaturas metafísicas, Adam se esconde em lugares remotos da Terra, procurando fugir dos demônios que o perseguem. Mas quando resolve voltar e perseguir aqueles que antes o perseguiam, o cenário apresenta outra realidade. Apesar da maioria das cenas mostrarem construções antigas, com arquitetura gótica e casas de madeira ou de pedra, no que parece ser a Europa medieval, em vários momentos são apresentadas na vestimenta dos atores, em letreiros de empresas, nos bares, nos túneis de metrô e no comportamento dos personagens aspectos que remetem à atualidade.

$\mathrm{Na}$ trama existe uma médica que trabalha para Naberius na tentativa de reviver os cadáveres humanos. Adam e esta médica vivem um rápido romance, mas o filme concentra a maior parte das suas cenas na luta entre os anjos e demônios, que encerra com a morte de Naberius pelas mãos de Adam, que faz no corpo de seu oponente a marca sagrada da ordem gárgula. Por fim, as gárgulas reestabelecem a paz e Adam fica livre para viver seu romance. 


\section{Adam, o nome dado ao monstro e seus pressupostos teológicos}

Até encontrar-se com a líder das gárgulas, a personagem Leonore, a criatura criada por Victor Frankenstein ainda não tem nome. Então, a líder da ordem gárgula denomina-o de Adam. Tal opção de nome, como é apresentado na história, possibilita a reflexão sobre esse discurso como combinação entre o que se fala, como aponta Charaudeau (2012, p.40), ao explicar que o discurso é a combinação entre o que se fala ou se escreve com a maneira a qual se fala ou escreve. Para Charaudeau, o discurso cria-se sempre a partir de dois polos.

No recorte das falas apresentado aqui, Leonore está como representante de Deus, dando o nome para a criatura sem identidade, e, em contrapartida, Adam figura o ser humano recebendo uma identificação da parte do divino. Para Charaudeau (2012, p.42), todo discurso representa o mundo ao evidenciar uma dada relação a partir de uma situação de troca. Na relação entre Leonore e Adam, o nome é escolhido para o personagem a partir do "já dito" presente no relato da criação nos primeiros capítulos de Gênesis. Há esta relação de troca de informação entre o ser humano criado por Deus e a criatura criada por Victor Frankenstein, explicitada pelo diretor do filme no momento em que a personagem Leonore dá a criatura o nome: Adam.

Bakhtin (2011, p. 297) afirma que "todo enunciado concreto é um elo na cadeia discursiva de um determinado campo", portanto a escolha do nome de Adam para a criatura, demonstra a inserção do significado teológico para o personagem, pois, de acordo com Bakhtin, os enunciados não são indiferentes entre si, tampouco se bastam em si mesmos, mas se conhecem uns aos outros e se refletem mutuamente.

Portanto, segundo a tradição judaico-cristã, Adam é o nome do primeiro homem criado por Deus, como registrado no livro do Gênesis ${ }^{4}$. Contudo, a palavra Adam, ao ser traduzida do texto original hebraico, significa "ser humano". Quando no filme é utilizado para o monstro de Frankenstein, o mesmo nome que a Bíblia usou para dar identidade ao ser humano, está posta a relação intertextual. Ou seja, o texto bíblico imbricado no texto cinematográfico propõe sentidos polissêmicos, dialógicos. O nome

\footnotetext{
${ }^{4}$ Ver: Gênesis 1.26 "Façamos o homem à nossa imagem, conforme a nossa semelhança". E Gênesis 3.20 "Adão deu a sua mulher o nome de Eva, pois ela seria mãe de toda a humanidade". No texto original em hebraico, antes do capítulo três e do relato da queda o autor bíblico usa a palavra ish (masculino/macho) para homem e isha (feminino/fêmea) para mulher. É no verso 20 do capítulo 3 que ish passa a ser denominado "Adam" (ser humano) e isha denominada "Ev" (mãe).
} 
do personagem principal do filme possibilita a apreensão de sentido de um discurso heterogêneo, já que o nome Adam traz consigo toda a bagagem teológica que o “Adam/ser humano" criado por Deus na Bíblia representado na construção de sentido da teologia.

Já a polifonia pode ser percebida no trecho do filme em que Adam, logo após ser criado, se rebela contra seu criador. E, sobre a polifonia Bakhtin (2011, p. 300), afirma que "em realidade, repetimos, todo enunciado, além do seu objeto, que sempre responde, de uma forma ou de outra aos enunciados do outro que o antecederam". Portanto, como texto polifônico a história do filme mostra a rebelião da criatura contra o seu criador, ao fazer referência intertextual ao texto bíblico que narra o personagem Adam da Bíblia se rebelando contra Deus no momento em que come do fruto da árvore proibida 5 .

Na narrativa de Gênesis, o Adam bíblico é expulso da presença do divino, ou seja, é separado de seu criador e a partir de então a Bíblia passa a relatar a trajetória deste homem exilado que tenta através de rituais se ligar novamente com seu criador. O filme analisado discorre sobre a trajetória de Adam em suas lutas internas de busca de sentido de sua existência, encontrando-se entremeio ao dualismo do bem e do mal, procurando saber de qual lado, ou contra quem, deve lutar. Essa crise existencial vivida pelo Adam do filme retrata a mesma crise enunciada no discurso bíblico de necessidade do ser humano se religar novamente com Deus, através de rituais religiosos ou de obediência a códigos morais. Quando identificada essa relação entre o personagem do filme e o personagem bíblico percebe-se o conceito de intertextualidade marcada elaborado por Bakhtin.

\section{A gárgula e a noite}

\footnotetext{
${ }^{5}$ Ver: Gênesis 3.6-7. "Quando a mulher viu que a árvore parecia agradável ao paladar, era atraente aos olhos e, além disso desejável para dela se obter discernimento, tomou do seu fruto, comeu-o e o deu ao seu marido, que comeu também. Os olhos dos dois se abriram, e perceberam que estavam nus, então juntaram folhas de figueira para cobrir-se" (Nova Versão Internacional). De acordo com a Teologia cristã este é o relato que registra o momento em que o ser humano desobedece a divindade pela primeira vez, Agostinho denomina-o como Pecado Original. É por consequência da desobediência que o ser humano é separado da divindade e passa a divagar sozinho pelo mundo, tendo contato com o sagrado, apenas através de rituais.
} 
Na Idade Média, quando as catedrais góticas foram construídas, em especial as francesas, os artistas modelaram suas esculturas baseando-se na teologia cristã. A proposta da arquitetura gótica surge com a intenção de intensificar os elementos da teologia cristã e seus fundamentos. Antes da engenharia gótica, as catedrais eram feitas em estilo românico, mais escuras e pouco arejadas. A arquitetura gótica é marcada pelo desenvolvimento das técnicas de colunas ogivais, arcobotantes e as abóbodas nervuradas, que possibilitaram a construção de catedrais muito mais altas com grandes paredes de vidros, aumentado a claridade no interior da construção ${ }^{6}$.

A palavra gárgula é oriunda do termo francês gargoullie, que traduzido para o português refere-se às calhas das residências, por onde a água da chuva escorre. $\mathrm{Na}$ imagem 1, percebe-se que na quina da estrutura das catedrais ficavam as gárgulas, que faziam a mesma função que as calhas nas residências. Mas, na arquitetura gótica as gárgulas das catedrais ganham formas inspiradas na quimera, que dentro da mitologia grega é um monstro híbrido resultante de duas espécies e com asas. Na concepção gótica, essas esculturas propõem o sentido de que os seres mitológicos (filosofia) ou espirituais (teologia) estariam observando os seres humanos o tempo todo, por isso, sempre aparecem acima dos pórticos das catedrais, com olhos esbugalhados como que se estivessem olhando em direção àqueles que adentram a igreja.

No filme, um dos cenários escolhidos é a catedral gótica Notre Dame de Paris, quartel general das criaturas do bem. As gárgulas do filme se transformam em seres vivos que combatem os demônios e protegem os seres humanos. Eles têm forma humana quando transitam no mundo real, mas tomam a forma de gárgula quando precisam lutar contra os demônios.

Martine Joly (1994, p. 13) diz que "imaginária ou concreta, a imagem passa por alguém, que a produz ou reconhece". A escolha das gárgulas para representação dos anjos mostra que o elemento discursivo é colocado na cadeia discursiva de forma autonímica, ou seja, o signo (gárgula) como ser metafísico retratado na arte gótica é apresentado no filme como esse mesmo ser. Contudo, na concepção gótica, a gárgula

${ }^{6}$ Disponível em: http://www.youtube.com/watch?v=GE2RduIJpvE. Acessado em22 de março de 2014. 
representava a criatura das trevas, mas no filme as gárgulas lutam a favor das leis divinas, ou seja, mantêm-se a referência ou signo, mas altera-se o significado.

A heterogeneidade entre o cinema, a teologia e a arquitetura é percebida nas gárgulas porque o cinema se utiliza de um elemento presente na arquitetura que foi construído com base na teologia e também porque esse mesmo elemento no cinema ocupa um papel discursivo inspirado na teologia. Outro elemento forte no filme é a noite. Todas as batalhas acontecem durante a noite ou em lugares obscuros. Inclusive, a catedral de Notre Dame, que em sua arquitetura tem a intenção de promover maior claridade interna, é escura em todas as cenas apresentadas, tendo, apenas, um feixe de luz adentrando o vitral principal, onde normalmente fica Leonore, orando a Deus.

Charaudeau (2012, p. 41) afirma que "toda forma remete a sentido, todo sentido remete a forma, numa relação de solidariedade recíproca". A noite, no filme, é um elemento fundamental para presentificar as relações discursivas propostas entre cinema e teologia, a partir de uma maneira específica de dizer, de enunciar. A enunciação da noite durante várias cenas do filme propõe sentidos que projetam a apreensão de sentido pelos telespectadores, pelo que eles já conhecem e reconhecem.

A noite representada pela escuridão das imagens rememora discursivamente aquele lugar que os seres humanos não veem ou não conseguem perceber, em especial as batalhas entre anjos e demônios ${ }^{7}$. Tanto a noite quanto a gárgula remetem a elementos presentes na tradição teológica. Nesta, os seres espirituais residem em trevas ou em luz e o homem no entremeio desses dois cenários. Mesmo sendo elementos semióticos a intertextualidade se revela a partir da teologia presente na arquitetura explicitada no cinema.

\section{Considerações finais}

A análise do roteiro do filme, retomado a partir dos conceitos de intertextualidade e polifonia, permitiu uma reflexão de áreas que a primeira vista não parecem tão próximas, como a teologia e o cinema. Entretanto, no intercâmbio de

\footnotetext{
${ }^{7}$ Ver: Efésios 6.12 “..., pois nossa luta não é contra seres humanos, mas contra os poderes e autoridades, contra os dominadores deste mundo de trevas, contra as forças espirituais do mal nas regiões celestiais" (Nova Versão Internacional). O apóstolo Paulo é o autor bíblico que mais discorre sobre uma latente batalha espiritual, que acontece diariamente no mundo invisível aos olhos humanos. Os gregos de Éfeso já estão habituados a este tipo de interpretação, que é oriunda do pensamento maniqueísta da luta entre o bem e o mal.
} 
conceitos de heterogeneidade e dialogismo do discurso foi possível notar que há relação entre os enunciados presentes tanto no filme quanto na Teologia cristã.

No primeiro recorte investigado o nome dado ao protagonista do filme explicita a heterogeneidade tanto entre Teologia e Cinema, compreendido como ciência, quanto da Literatura e do Cinema, entendido como arte. Ao usar o nome Adam o interlocutor traz a voz da Teologia Cristã e da Mitologia Judaica, provocando a polifonia entre o “já dito" da construção de sentido da teoria do criacionismo. Também presente na escolha do nome está a teoria bakhtiniana que aponta o enunciado como um elo na cadeia discursiva e a teoria de Charradeau que compreende o enunciado ganhando significado a partir de onde e da maneira como é dito. No caso do filme Adam é uma criatura nominada por um ser imortal, a Leonore, assim como, no caso do Adam bíblico que é nominado por Deus.

No segundo recorte, a Gárgula e a Noite, foi possível perceber intertextualidade implícita entre Teologia e Arquitetura apresentada através de elementos cinematográficos, como o ser mítico sendo um guerreiro divino numa realidade não visível ao mundo real.

Também no recorte da noite faz-se a enunciação do que os telespectadores já reconhecem, como sombrio, misterioso e abscondido, sendo o cenário propício para as batalhas espirituais. Neste aspecto que se apresenta a teoria de Charradeau da forma que remete ao sentido e o sentido que remete a forma.

Para desenvolver uma análise coerente do filme foram necessárias algumas reconstruções de sentido, com intenção de relacionar o enunciado teológico com o enunciado cinematográfico, como a transliteração da palavra Adam e também a proposta inovadora da engenharia gótica.

Percebeu-se a as várias vozes atuando em ambos os recortes do filme, principalmente a teologia que por vezes aparecia marcada, como é o caso do nome do personagem, ou implícita, como o caso de estar presente no fundamento filosófico da arquitetura gótica que teve como principal representante a gárgula.

Apesar de limitada em apenas dois recortes, a pesquisa atingiu seu objetivo que era apontar os pressupostos teológicos a partir da Análise do Discurso do filme Frankenstein: Entre anjos e demônios. 


\section{Referências}

AUTHIER-REVUZ, Jacqueline. Heterogeneidade(s) Enunciativa(s). Campinas: Cad. Est. Ling. 25-42, 1990.

BAKHTIN, Mikhail. Estética da Criação Verbal. São Paulo: Martins Fontes, 2011. BÍBLIA. Bíblia Sagrada: nova versão internacional. Trad. comissão de tradução da Sociedade Bíblica Internacional. São Paulo: Sociedade Bíblica Internacional, 2012. CHARAUDEAU, Patrick. Discurso das Mídias. São Paulo: Contexto, 2012. JOLY, Martine. Introdução à Análise da Imagem. Lisboa: Edições 70, 2007. 